Stephan Fedler · Der Aphorismus 


\section{Stephan Fedler}

\section{Der Aphorismus}

\section{Begriffsspiel zwischen Philosophie und Poesie}


CIP-Titelaufnahme der Deutschen Bibliothek

\section{Fedler, Stephan:}

Der Aphorismus: Begriffsspiel zwischen Philosophie und Poesie/Stephan Fedler. Stuttgart: M und P, Verl. für Wiss. und Forschung, 1992

(M\&P Schriftenreihe für Wissenschaft und Forschung)

Zugl.: Wuppertal, Univ., Diss., 1990

ISBN 978-3-476-45014-2

\section{ISBN 978-3-476-45014-2}

ISBN 978-3-476-04172-2 (eBook)

DOI 10.1007/978-3-476-04172-2

Dieses Werk ist einschließlich aller seiner Teile urheberrechtlich geschützt. Jede Verwertung außerhalb der engen Grenzen des Urheberrechtsgesetzes ist ohne Zustimmung des Verlages unzulässig und strafbar. Das gilt insbesondere für Vervielfältigungen, Übersetzungen, Mikroverfilmung und Einspeicherung in elektronischen Systemen.

M\&P Verlag für Wissenschaft und Forschung ein Verlag der J. B. Metzlerschen Verlagsbuchhandlung und Carl Ernst Poeschel Verlag GmbH in Stuttgart"

(C) 1992 Springer-Verlag GmbH Deutschland Ursprünglich erschienen bei J. B. Metzlersche Verlagsbuchhandlung und Carl Ernst Poeschel Verlag GmbH in Stuttgart 1992 
Inhalt

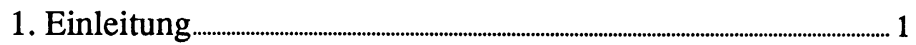

2. Die Isolierbarkeit von Aphorismen als Problem philosophisch-poetischer Sprache ....................................................... 11

2.1. Schopenhauers "Aphorismen zur Lebensweisheit".......................................... 11

2.2. Probleme der Aphorismusforschung .................................................................... 21

2.3. "Isolation" - Frickes Aphorismusdefinition.......................................................... 25

2.4. Isolierbarkeit - Die Bedingungen der Isolation ............................................... 33

2.5. Die Präsentation von Aphorismen ............................................................................. 36

2.6. Bedingung der Isolation - Allgemeine Begriffe ............................................ 40

3. Das semantische Zentrum - Begriffskombination......................... 48

3.1. Aphoristische Verkürzung ……....................................................................... 48

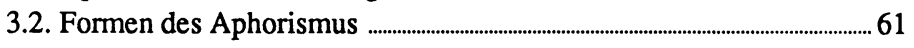

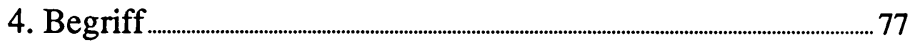

4.1. Begriff und Text - Die philosophische Sprache …….......................................77

4.2. Aphorismus und Begriff .............................................................................................. 94

5. Techniken des Begriffsspiels ...............................................................99

5.1. Paradox - Banalität - Frage ………………………………………………....99

5.2. Anspielung - Kontrafaktur - Antithese ...................................................... 114

5.3. Definition - Allaussage - "Er-Aphorismen" Lebensregel ................................................................................................................. 127

5.4. Wortspiel - Superlativ - Neologismus ...................................................... 138

5.5. Offenlassen - Hintersinn - Entlarvung .................................................... 145

5.6. Proportion - Priamel - Exempel .................................................................... 153

5.7. Parataxe - Vergleich - Metapher - Schlußpointe ……........................ 161 
6. Begriffsspiel - Zwischen Philosophie und Poesie..................... 177

6.1. Die Funktion des Begriffspiels - Pointe ....................................................... 177

6.2. Frickes "Gattungsdefinition" ................................................................ 182

6.3. Begriffsspiel - Gattung oder Schreibweise? ......................................... 185

6.4. Aphorismus - Ein Familienähnlichkeitsbegriff ..................................... 189

6.5. Begriffsspiel - Ein Struktur- und Beschreibungsbegriff .................... 195

6.6. Hölderlins Roman "Hyperion" - Ein Begriffsspiel ................................ 198

6.7. Begriffsspiel - Allgemeines und Besonderes ......................................... 202

6.8. Philosophie, Poesie und Literaturwissenschaft .................................. 213 